\title{
Avant-propos
}

\section{Françoise Curtit}

\section{OpenEdition}

Journals

Édition électronique

URL : https://journals.openedition.org/rdr/1418

DOI : $10.4000 /$ rdr 1418

ISSN : 2534-7462

\section{Éditeur}

Presses universitaires de Strasbourg

\section{Édition imprimée}

Date de publication : 6 mai 2021

Pagination : 7-9

ISBN : 979-10-344-0089-8

ISSN : 2493-8637

\section{Référence électronique}

Françoise Curtit, « Avant-propos », Revue du droit des religions [En ligne], 11 | 2021, mis en ligne le 06 mai 2021, consulté le 03 mai 2022. URL : http://journals.openedition.org/rdr/1418 ; DOI : https:// doi.org/10.4000/rdr.1418

\section{(c) $(1)(9$}

La revue du droit des religions est mise à disposition selon les termes de la Creative Commons Attribution - Pas d'Utilisation Commerciale 4.0 International - CC BY-NC 4.0. 


\section{Avant-propos}

À la différence d'autres pays européens, il n'y a pas en France de facultés de théologie dans les universités publiques, hormis à Strasbourg. Cette situation s'explique à la fois par un contexte historique spécifique et par le cadre juridique de la laicité qui semble obérer les conditions d'un enseignement public de la théologie. Cette question a été relancée depuis quelques décennies dans le cadre de réflexions menées au sujet de la formation des personnels religieux musulmans et de la place des sciences de l'islam à l'université. Les débats sur les possibilités de création d'une faculté de théologie musulmane conduisent ainsi à réexaminer dans son ensemble le statut de la théologie au sein de l'enseignement supérieur.

L'organisation de l'enseignement supérieur en France est encore largement tributaire des revirements politiques intervenus au cours du XIX ${ }^{\mathrm{e}}$ siècle alors que se sont succédé des gouvernements alternant entre cléricalisme et anticléricalisme. Les facultés de théologie catholique et protestante fondées dans le cadre de l'Université impériale furent supprimées de l'Université républicaine respectivement en 1885 et en 1905, alors que les débuts de la Troisième république voyaient aussi l'émergence des universités libres (B. BasdevantGaudemet, Histoire des facultés de théologie des universités publiques en France). Cet héritage historique a conduit à l'instauration durable d'une «privatisation» de la formation des ministres du culte, dispensée par les différentes confessions dans leurs propres établissements. Les conditions d'un enseignement de la théologie dans l'enseignement supérieur public sont néanmoins réévaluées aujourd'hui à l'occasion de projets envisageant la création d'une faculté de théologie musulmane au sein de l'Université publique. Il s'agit alors de s'interroger sur la compatibilité de cette ambition avec le cadre juridique actuel, au regard notamment du droit universitaire, du principe de laïcité ou de la question de l'interdiction des subventions au culte (P.-H. Prélot, Étude juridique sur les possibilités de création d’une faculté de théologie musulmane dans le cadre français). 
L'exception que constituent les facultés de théologie catholique et protestante de l'université de Strasbourg et le département de théologie de l'université de Lorraine établit un contexte intellectuel et culturel considéré comme particulièrement propice à la réflexion sur l'enseignement de la théologie et son ouverture à d'autres cultes. L'analyse des règles de droit local applicables et des garanties constitutionnelles du maintien de cet enseignement permet d'éclairer ces questionnements au-delà des départements d'Alsace et de Moselle (J.-M. Woehrling, Statut juridique de l'enseignement universitaire de la théologie et droit local alsacien-mosellan). C'est en s'attachant par ailleurs à l'organisation et au fonctionnement concret des activités d'enseignement et de recherche de la faculté de théologie catholique de l'université de Strasbourg que l'on peut approcher la position originale de la théologie au croisement des sciences humaines et des convictions religieuses et illustrer la spécificité relative d'une composante assumant l'adjectif «catholique»au sein d'une université publique (D. Fricker, La faculté de théologie catholique de l'université de Strasbourg. Une approche empirique).

Ces problématiques ne sont pas propres à la France et nombre de pays européens ont récemment créé - ou envisagent la création - de nouvelles filières de théologie. En Belgique, les pouvoirs publics ont déployé des formations alliant théologie musulmane et sciences sociales et réfléchissent désormais à la création d'une faculté de théologie musulmane dans un paysage de l'enseignement universitaire "pilarisé» qui confère un statut stable à la théologie catholique et à la morale laïque mais une place largement plus incertaine aux formations des confessions minoritaires (L.-L. Christians, Théologie(s) et morale(s) laïque(s) dans les structures de l'enseignement supérieur en Belgique). Au-delà des disparités nationales, la jurisprudence de la Cour européenne des droits de l'homme permet d'évoquer des principes juridiques communs relatifs au rôle des États en matière de création de facultés de théologie. Les principes généraux du droit à l'instruction et les modalités d'encadrement des droits et devoirs des enseignants professant sous le contrôle d'autorités religieuses mettent en effet en évidence une grande latitude accordée aux États qui demeurent libres de créer des enseignements de théologie dans les universités publiques, sans qu'il puisse s'agir d'une obligation positive mise à leur charge (G. Gonzalez, L'enseignement universitaire de la théologie devant la Cour européenne des droits de l'homme).

Les contributions réunies dans ce dossier concourent ainsi à enrichir une réflexion sur la place de la théologie à l'université entamée de longue date, sans prétendre à épuiser un débat qui continue de se nourrir de multiples approches et points de vue. 
Les varia qui complètent ce numéro reflètent l'engagement de la Revue $d u$ droit des religions à rendre compte des relations entre droit et religion au-delà des frontières européennes: S. Bernatchez détaille le recours à des innovations juridiques empruntées au droit américain dans le cadre de la gouvernance des religions au Canada et $\mathrm{M}$. Wada illustre la portée du principe constitutionnel de séparation entre l'État et les religions au Japon. L'actualité s'invite pour finir avec la chronique de F. Dieu qui revient sur la liberté de culte en période d'urgence sanitaire et celle de G. Gonzalez qui analyse la jurisprudence récente de la Cour européenne des droits de l'homme à propos de l'objection de conscience en milieu scolaire et de la restriction d'accès à l'enseignement à domicile.

Françoise CURTIT 